\title{
Synthesis, Characterization and Thermal Behavior Study of New 1,2,3-Triazole Derivatives Containing 1,3,4-Oxadiazole Ring
}

\author{
RIYADH J. NAHI* and ZAINAB I. KUWAIT \\ Department of Chemistry, College of Science, Al-Muthanna University, Iraq. \\ *Corresponding author E-mail: riyadhnahi@yahoo.com \\ http://dx.doi.org/10.13005/ojc/350153
}

(Received: December 07, 2018; Accepted: January 28, 2019)

\begin{abstract}
In this present work, a series of new 1-(substituted-phenyl)-1H-1,2,3-triazolyl-4-carboxylic acid derivatives was synthesized via copper (I) catalyzed azide-alkyne cycloaddition reaction. Since these synthesized 1,2,3-triazole compounds containing a carboxyl functional group, it was exploited for the combination of 1,2,3-triazole ring with 1,3,4-oxadiazole ring system in one molecule. Thus, the synthesized 1,2,3-triazoles were the key starting materials to synthesize the target compounds via a condensation reaction with semicarbazide hydrochloride in the presence of $\mathrm{POCl}_{3}$. Furthermore, the thermal behavior of all newly heterocyclic compounds was also studied by TGA and DTG techniques.
\end{abstract}

Keywords: Heterocyclic, 1,2,3-Triazole, 1,3,4-Oxadiazole, Click reaction,

1,3-Dipolarcycloaddition, Thermal study.

\section{INTRODUCTION}

The knowledge of chemistry of heterocyclic compounds represents a basic point for the development of new heterocycles compounds that have an important role in agrochemical, pharmaceuticals and materials science ${ }^{1-3}$. Interestingly, azole structures being the most common among different classes of heterocyclic compounds ${ }^{4}$. Structurally, azoles are composed of five-membered rings containing nitrogen atom and at least one other non-carbon atom of either nitrogen, oxygen or sulphur as heteroatoms as shown in Figure $1^{5,6}$.

$$
\sum_{\mathrm{N}^{-N}}^{O}
$$

1,2,3-oxadiazole<smiles>c1nc[nH]n1</smiles>

1,2,4-triazole<smiles>c1cnon1</smiles>

1,2,4-oxadiazole 1,2,5-oxadiazole<smiles>c1c[nH]nn1</smiles><smiles>c1nnco1</smiles>

1,2,3-triazole 1,3,4-oxadiazole

Fig. 1. Different structures of azole

Currently, 1,2,3-triazole and 1,3,4-oxadiazole derivatives have a special attention due to their remarkable biological, chemical and physical

This is an Open Access article licensed under a Creative Commons license: Attribution 4.0 International (CC- BY). Published by Oriental Scientific Publishing Company @ 2018

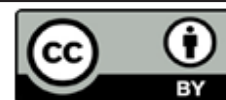


properties $^{7-9}$. In general, 1,2,3-triazole ring system is one of two aromatic isomeric structures of the general formula $\mathrm{C}_{2} \mathrm{~N}_{2} \mathrm{OH}_{2}{ }^{10}$. Currently, click reaction is a method choice for the synthesis of 1,2,3-triazole ring $^{11-13}$. This click reaction is described as a copper (I) catalyzed azide-alkyne 1,3-dipolarcycloaddition (CUAAC) and a simple synthetic route in relatively high yields with high regioselectivity to produce 1,4disubstituted-1,2,3-triazole derivatives ${ }^{14-16}$. While, 1,3,4-oxadiazole ring system can be described as one of four isomers that have the molecular formula $\mathrm{C}_{2} \mathrm{~N}_{2} \mathrm{OH}_{2}{ }^{17,18}$. Depending on the starting materials that are used, several synthetic routes have been followed in the literatures for the synthesis of 1,3,4oxadiadole derivatives ${ }^{19,20}$. However, the common synthetic approach is a cyclization reaction of the intermediate acylsemicarbazides in the presence of a variety of dehydrating agents such as thionyl chloride and polyphosphoric acid to introduce 2-amino-1,3,4oxadiazole derivatives ${ }^{21,22}$. As the combination of two or more pharmacophores in one molecule is a strategy for development of new compounds, we are interested in synthesizing a new heterocyclic compounds containing 1,2,3-triazole and 1,3,4oxadiazole rings combined in one molecule.

\section{EXPERIMENTAL}

\section{Chemicals and Instruments}

All solvents and starting materials were purchased from commercially available sources and they were directly used without further purification. FT-IR spectra were recorded on an FT-IR-8400S plus spectrometer operating from $4000-500 \mathrm{~cm}^{-1}$ as $\mathrm{KBr}$ disc. ${ }^{1} \mathrm{H}-\mathrm{NMR}$ spectra were recorded at $500 \mathrm{MHz}$ on a Bruker AC400 spectrometer. Mass data were measured on Agilent Technology (HP). TG-DTG analysis was performed by using a Perkin Elmer TG 4000 at the temperature ranged $39-900^{\circ} \mathrm{C}$, with flow rate $20 \mathrm{ml} / \mathrm{min}$ and heating rate $40^{\circ} \mathrm{C} / \mathrm{min}$ under nitrogen current.

\section{Procedures}

Synthesis of substituted phenyl azides (1-5)

All phenyl azides that were used in the present work were synthesized according to the modified procedure that was described in the literature ${ }^{23}$.

\section{General procedure for the synthesis of 1,2,3-triazole derivatives (6-10)}

To a stirred aqueous solution containing
$\mathrm{CuSO}_{4} .5 \mathrm{H}_{2} \mathrm{O}(0.25 \mathrm{~g}, 1.03 \mathrm{mmol})$ and sodium ascorbate $(0.38 \mathrm{~g}, 1.93 \mathrm{mmol})$, a mixture of tert-butanol:water $(30.0 \mathrm{ml} 2: 1)$ was added. To the resulted solution, propiolic acid $(1.2 \mathrm{ml}, 20.0 \mathrm{mmol})$ and a substituted-phenyl azide $(20.0 \mathrm{mmol})$ were added, sequentially. The reaction mixture was then stirred at $50^{\circ} \mathrm{C}$ for overnight. The reaction mixture was then allowed to cool into room temperature before addition of water $(100 \mathrm{ml})$. The formed precipitate was then collected by filtration under vacuum, washed with ether and dried to give the titled compounds as solid products.

Synthesis of 1-(3-methoxyphenyl)-1H-1,2,3triazolyl-4-carboxylic acid (6)

It was prepared by using 1-azido-3-methoxybenzene 1 (2.98 g, $20.0 \mathrm{mmol})$ : Yield (3.3 g, 77\%) as a gray solid. FT-IR(KBrdisc, $\left.\mathrm{cm}^{-1}\right), 3576-2400(\mathrm{OH}, \mathrm{COOH})$, 3136 (Ar-H), 2947 (C-H, aliphatic), 1706 (C=O), 1647 (C=C-triazole), $1612(\mathrm{Ar}, \mathrm{C}=\mathrm{C})$ and $1422(-\mathrm{N}=\mathrm{N}-) .{ }^{1} \mathrm{H}-\mathrm{NMR}$ $\left(500 \mathrm{MHz}, \mathrm{DMSO}-\mathrm{d}_{6}\right): \delta=3.4\left(\mathrm{~s}, 3 \mathrm{H}, \mathrm{OCH}_{3}\right), 7.49-7.57$ (m, 4H, Ar-H) and 9.4 (s, 1H, C=CH-triazolyl). HPMS-El ${ }^{+}$ $(\mathrm{m} / \mathrm{z})$ : Calc. for $\mathrm{C}_{10} \mathrm{H}_{9} \mathrm{~N}_{3} \mathrm{O}_{3}=219.06$, found $=219.1$.

Synthesis of 1-(3-methylphenyl)-1H-1,2,3triazolyl-4-carboxylic acid (7)

It was prepared by using 1-azido-3-methylbenzene 2 (2.66 g, $20.0 \mathrm{mmol}$ ): Yield (2.03 g, 50\%) as a gray solid. FT-IR ( $\mathrm{KBr}$ disc, $\left.\mathrm{cm}^{-1}\right), 3525-2400$ (OH, COOH), 3063 (Ar-H), 2922 (C-H aliphatic), 1708 (C=O), 1654 (C=C-triazole), 1619 (Ar, C=C) and $1383(-\mathrm{N}=\mathrm{N}-)$. ${ }^{1} \mathrm{H}-\mathrm{NMR}\left(500 \mathrm{MHz}\right.$, DMSO- $\left.\mathrm{d}_{6}\right)$ : $\delta=2.1\left(\mathrm{~s}, 3 \mathrm{H}, \mathrm{CH}_{3}\right), 6.6-7.8(\mathrm{~m}, 4 \mathrm{H}, \mathrm{Ar}-\mathrm{H})$ and 8.89 (s, $1 \mathrm{H}, \mathrm{C}=\mathrm{CH}$-triazolyl). HPMS-El ${ }^{+}(\mathrm{m} / \mathrm{z})$ : Calc. for $\mathrm{C}_{10} \mathrm{H}_{9} \mathrm{~N}_{3} \mathrm{O}_{2}=203.07$, found $=203.1$.

Synthesis of 1-(3-nitrophenyl)-1H-1,2,3-triazolyl4-carboxylic acid (8)

It was prepared by using 1-azido-3-nitrobenzene 3 (3.8 g, $20.0 \mathrm{mmol})$ : Yield (3.9 g, 84\%) as light green solid. FT-IR (KBr disc, $\left.\mathrm{cm}^{-1}\right)$, 3500-2500 (OH, $\mathrm{COOH}$ ), $3113(\mathrm{Ar}-\mathrm{H}), 1695$ (C=O, COOH), 1631 (C=Ctriazole), 1594 ( $\mathrm{Ar}, \mathrm{C}=\mathrm{C}), 1390(-\mathrm{N}=\mathrm{N}-)$ and 1315, 1257 (asymmetric, symmetric $\mathrm{NO}_{2}$ ). ${ }^{1} \mathrm{H}-\mathrm{NMR}(500$ $\left.\mathrm{MHz}, \mathrm{DMSO}-\mathrm{d}_{6}\right): \delta=13.3(\mathrm{~s}, 1 \mathrm{H}, \mathrm{COOH}), 7.9-8.9(\mathrm{~m}$,

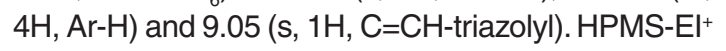
$(\mathrm{m} / \mathrm{z})$ : Calc. for $\mathrm{C}_{9} \mathrm{H}_{6} \mathrm{~N}_{4} \mathrm{O}_{4}=234.04$, found $=234.01$.

Synthesis of 1-(2-nitrophenyl)-1H-1,2,3-triazolyl4-carboxylic acid (9)

It was prepared by using 1-azido-2-nitrobenzene 4 (3.8 g, 20.0 mmol): Yield (3.4 g, 70\%) 
as a gray solid. FT-IR ( $\mathrm{KBr}$ disc, $\left.\mathrm{cm}^{-1}\right), 3500-2700$ $(\mathrm{OH}, \mathrm{COOH}), 3115(\mathrm{Ar}-\mathrm{H}), 1720(\mathrm{C}=\mathrm{O}), 1608$ (C=Ctriazole), 1589 (Ar, $\mathrm{C}=\mathrm{C}), 1404(-\mathrm{N}=\mathrm{N}-), 1356$ and 1313 (asymmetric, symmetric $\left.\mathrm{NO}_{2}\right) .{ }^{1} \mathrm{H}-\mathrm{NMR}(500$ $\left.\mathrm{MHz}, \mathrm{DMSO}-\mathrm{d}_{6}\right): \delta=7.3-8.4(\mathrm{~m}, 4 \mathrm{H}, \mathrm{Ar}-\mathrm{H})$ and 8.7 (s, $1 \mathrm{H}, \mathrm{C}=\mathrm{CH}$-triazolyl). HPMS-El ${ }^{+}(\mathrm{m} / \mathrm{z})$ : Calc. for $\mathrm{C}_{9} \mathrm{H}_{6} \mathrm{~N}_{4} \mathrm{O}_{4}=234.04$, found $=234.0$.

\section{Synthesis of 1-(4-bromophenyl)-1H-1,2,3-triazole- 4-carboxylic acid (10) \\ It was prepared by using 1-azido-4-bromo-} benzene 5 (3.96 g, $20.0 \mathrm{mmol}$ ): Yield (4.7 g, 88\%) as a white solid. FT-IR ( $\mathrm{KBr}$ disc, $\left.\mathrm{cm}^{-1}\right), 3500-2400$ $(\mathrm{OH}, \mathrm{COOH}), 3128(\mathrm{Ar}-\mathrm{H}), 1705(\mathrm{C}=\mathrm{O}), 1656(\mathrm{C}=\mathrm{C}-$ triazole), $1591(\mathrm{Ar}, \mathrm{C}=\mathrm{C}), 1413(-\mathrm{N}=\mathrm{N}-)$ and 825 (C-Br). ${ }^{1} \mathrm{H}-\mathrm{NMR}\left(500 \mathrm{MHz}, \mathrm{DMSO}-\mathrm{d}_{6}\right): \delta=13.2(\mathrm{~s}, 1 \mathrm{H}$, $\mathrm{COOH}), 7.6-8.8(\mathrm{~m}, 4 \mathrm{H}, \mathrm{Ar}-\mathrm{H})$ and $9.1(\mathrm{~s}, 1 \mathrm{H}, \mathrm{C}=\mathrm{CH}-$ triazolyl). HPMS-El ${ }^{+}(\mathrm{m} / \mathrm{z})$ : Calc. for $\mathrm{C}_{9} \mathrm{H}_{6} \mathrm{BrN}_{3} \mathrm{O}_{2}=$ 266.96 , found $=266.07$.

General procedure for synthesis of $1,3,4$ oxadiazoles derivatives (11-15)

An appropriate 1,2,3-triazole derivative (6-10) (10.0 mmol) and semicarbazide hydrochloride $(1.11 \mathrm{~g}, 10.0 \mathrm{mmol})$ were dissolved in $\mathrm{POCl}_{3}$ $(25 \mathrm{ml})$. The resulting reaction mixture was refluxed for overnight. The reaction mixture was then allowed to cool into room temperature before being slowly poured onto crush-ice $(200 \mathrm{~g})$. The formed precipitate was stirred in the same solution for 15 min before being treated carefully with an aqueous solution of sodium hydroxide $50 \%$. The precipitate was then collected by filtration under vacuum, washed with water and dried.

Synthesis of 2-amino-5-[1-(3-methoxyphenyl)1H-1,2,3-triazol-4-yl]-1,3,4-oxadiazole (11)

It was prepared by using compound 6 $(2.19 \mathrm{~g}, 10.0 \mathrm{mmol})$ : Yield $(2.1 \mathrm{~g}, 85 \%)$ as a light green solid. FT-IR ( $\mathrm{KBr}$ disc, $\left.\mathrm{cm}^{-1}\right), 3136(\mathrm{Ar}-\mathrm{H})$, $1653(\mathrm{C}=\mathrm{N}), 1610$ (C=C-triazole), 1595 (Ar, C=C) and $1440(\mathrm{~N}=\mathrm{N}) .{ }^{1} \mathrm{H}-\mathrm{NMR}\left(500 \mathrm{MHz}, \mathrm{DMSO}-\mathrm{d}_{6}\right): \delta=$ $3.7\left(\mathrm{~s}, 3 \mathrm{H}, \mathrm{OCH}_{3}\right), 4.3\left(\mathrm{~s}, 2 \mathrm{H}, \mathrm{NH}_{2}\right), 7.0-7.9(\mathrm{~m}, 4 \mathrm{H}$, $\mathrm{Ar}-\mathrm{H})$ and $8.8\left(\mathrm{~s}, 1 \mathrm{H}, \mathrm{C}=\mathrm{CH}\right.$-triazolyl). $\mathrm{HPMS}^{-\mathrm{El}^{+}}$ $(\mathrm{m} / \mathrm{z})$ : Calc. for $\mathrm{C}_{9} \mathrm{H}_{7} \mathrm{~N}_{3} \mathrm{O}_{3}=258.09$, found $=258.01$.

Synthesis of 2-amino-5-[1-(3-methylphenyl)-1H1,2,3-triazol-4-yl]-1,3,4-oxadiazole (12)

It was prepared by using compound 7 (2.03 g, $10.0 \mathrm{mmol})$ : Yield (2.17 g, 90\%) as a dark green solid. FT-IR ( $\mathrm{KBr}$ disc, $\left.\mathrm{cm}^{-1}\right), 3059$ (Ar-H),
$1626(\mathrm{C}=\mathrm{N}), 1595$ (C=C-triazole), $1558(\mathrm{Ar}, \mathrm{C}=\mathrm{C})$ and $1363(-\mathrm{N}=\mathrm{N}-)$. ${ }^{1} \mathrm{H}-\mathrm{NMR}\left(500 \mathrm{MHz}\right.$, DMSO- $\left.\mathrm{d}_{6}\right)$ : $\delta=2.0\left(\mathrm{~s}, 3 \mathrm{H}, \mathrm{CH}_{3}\right), 7.3-7.9(\mathrm{~m}, 4 \mathrm{H}, \mathrm{Ar}-\mathrm{H})$ and 8.7 (s, $1 \mathrm{H}, \mathrm{C}=\mathrm{CH}$-triazolyl). HPMS-El+ (m/z): Calc. for $\mathrm{C}_{11} \mathrm{H}_{10} \mathrm{~N}_{6} \mathrm{O}=242.09$, found $=242.01$.

Synthesis of 2-amino-5-[1-(3-nitrophenyl)-1H1,2,3-triazol-4-yl]-1,3,4-oxadiazole (13)

It was prepared by using compound 8 (2.34 g, $10.0 \mathrm{mmol})$ : Yield (2.0 g, 74\%) as a green solid. FT-IR ( $\mathrm{KBr}$ disc, $\left.\mathrm{cm}^{-1}\right), 3113(\mathrm{Ar}-\mathrm{H}), 1664$ $(\mathrm{C}=\mathrm{N}), 1632$ (C=C-triazole), $1593(\mathrm{Ar}, \mathrm{C}=\mathrm{C})$ and $1352(-\mathrm{N}=\mathrm{N}) .{ }^{1} \mathrm{H}-\mathrm{NMR}\left(500 \mathrm{MHz}, \mathrm{DMSO}-\mathrm{d}_{6}\right): \delta=$ $4.36\left(\mathrm{~s}, 2 \mathrm{H}, \mathrm{NH}_{2}\right), 7.4-8.02(\mathrm{~m}, 4 \mathrm{H}, \mathrm{Ar}-\mathrm{H})$ and 8.8 (s, $1 \mathrm{H}, \mathrm{C}=\mathrm{CH}$-triazolyl). HPMS-El ${ }^{+}(\mathrm{m} / \mathrm{z})$ : Calc. for $\mathrm{C}_{10} \mathrm{H}_{7} \mathrm{~N}_{7} \mathrm{O}_{3}=273.06$, found $=273.0$.

Synthesis of 2-amino-5-[1-(2-nitrophenyl)-1H1,2,3-triazol-4-yl]-1,3,4-oxadiazole (14)

It was prepared using compound 9 (2.34 g, $10.0 \mathrm{mmol}$ ): Yield (1.99 g, 73\%) as a brown solid. FT-IR ( $\mathrm{KBr}$ disc, cm$\left.{ }^{-1}\right), 3119(\mathrm{Ar}-\mathrm{H}), 1653(\mathrm{C}=\mathrm{N})$, 1608(C=C-triazole), $1590(\mathrm{Ar}, \mathrm{C}=\mathrm{C})$ and 1348 $(-\mathrm{N}=\mathrm{N}-) .{ }^{1} \mathrm{H}-\mathrm{NMR}\left(500 \mathrm{MHz}, \mathrm{DMSO}-\mathrm{d}_{6}\right): \delta=4.9(\mathrm{~s}$, $\left.2 \mathrm{H}, \mathrm{NH}_{2}\right), 7.3-8.2(\mathrm{~m}, 4 \mathrm{H}, \mathrm{Ar}-\mathrm{H})$ and $8.72(\mathrm{~s}, 1 \mathrm{H}$, $\mathrm{C}=\mathrm{CH}$-triazolyl). $\mathrm{HPMS}-\mathrm{El}^{+}(\mathrm{m} / \mathrm{z})$ : Calc. for $\mathrm{C}_{10} \mathrm{H}_{7} \mathrm{~N}_{7} \mathrm{O}_{3}$ $=273.06$, found $=273.1$.

Synthesis of 2-amino-5-[1-(4-bromophenyl)-1H1,2,3-triazol-4-yl]-1,3,4-oxadiazole(15)

It was prepared by using compound 10 (2.68 g, $10.0 \mathrm{mmol})$ :Yield (2.42 g, 79\%), as a green solid. FT-IR ( $\mathrm{KBr}$ disc, $\left.\mathrm{cm}^{-1}\right), 3126(\mathrm{Ar}-\mathrm{H}), 1654$ $(\mathrm{C}=\mathrm{N}), 1595$ (C=C-triazole), $1560(\mathrm{Ar}, \mathrm{C}=\mathrm{C})$ and 1435 (-N=N-). ${ }^{1} \mathrm{H}-\mathrm{NMR}(500 \mathrm{MHz}$, DMSO-d $)$ : $\delta=$ $4.37\left(\mathrm{~s}, 2 \mathrm{H}, \mathrm{NH}_{2}\right), 7.4-7.99(\mathrm{~m}, 4 \mathrm{H}, \mathrm{Ar}-\mathrm{H})$ and 8.86 (s, $1 \mathrm{H}, \mathrm{C}=\mathrm{CH}$-triazolyl). HPMS-El ${ }^{+}(\mathrm{m} / \mathrm{z})$ : Calc. for $\mathrm{C}_{10} \mathrm{H}_{7} \mathrm{BrN}_{6} \mathrm{O}=307.98$, found $=308.1$.

\section{RESULTS AND DISCUSSION}

\section{Chemistry}

For the synthesis of the target 1,3,4-triazole derivatives 6-10, a series of electron-rich and poor p-, o- and m-substituted phenyl azido compounds 1-5 was designed as azido components for CuAAC reaction. These intermediates were synthesized via reaction of diazonium salts with sodium azide (Scheme 1) according to the procedure that was described in the literature ${ }^{23}$. Choosing of these different azides is to investigate the effect of the 
nature and position of the substituent group on the reactivity of their corresponding azides towards click reaction and on the thermal stability of the synthesized compounds 6-15. Thus, following our previous investigations, the synthetic route involved addition of propiolic acid and an appropriate azide $1-5$ to a solution of tert-butanol:water (2:1) containing $\mathrm{CuSO}_{4} \cdot 5 \mathrm{H}_{2} \mathrm{O}$ and sodium ascorbate as described in Scheme 1.

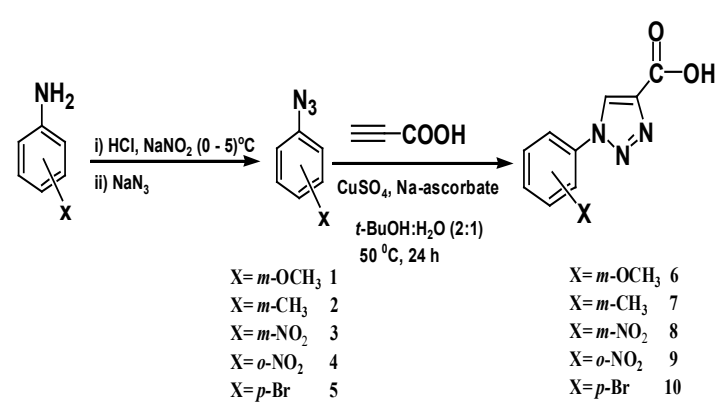

Scheme 1. Synthesis of 1,2,3-triazole derivatives

Sodium ascorbate was used as a reducing agent to produce in situ $\mathrm{Cu}$ (I) that is required to perform a copper (I) catalyzed azide-alkyne cycloaddition reaction and this reaction is proceeded according to the general suggested mechanism that is describe in Scheme 2.

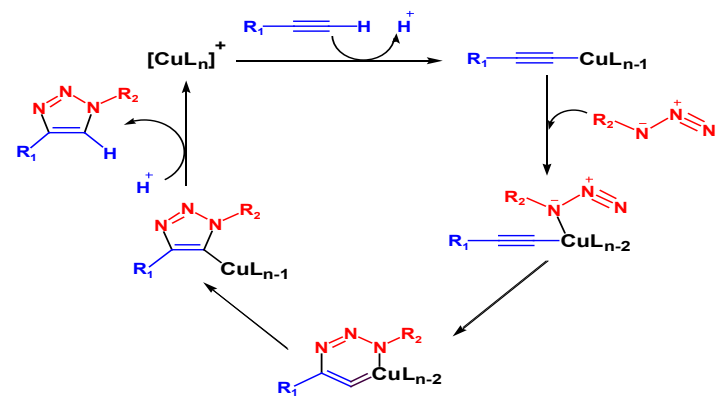

Scheme 2. A general mechanism for the synthesis of 1,2,3-triazole derivatives ${ }^{24}$

The reaction mixture was heated up to $50^{\circ} \mathrm{C}$ and left to stir for overnight. By the first attempt, all synthesized m-, $\mathrm{p}$ - and o-substituted phenyl azides displayed a reactivity towards click reaction to give the titled compounds 6-10 in a relatively high yield. Our synthetic pathway highlighted a simple work up and the target products 6-10 were separated as precipitates from the reaction mixture as pure compounds with no need to purification by column chromatography. All newly synthesized compounds were characterized by FT-IR, ${ }^{1} \mathrm{H}-\mathrm{NMR}$ and Mass spectra.

As the synthesized 1,2,3-triazole derivatives 6-10 containing a carboxyl function group, so it can be used to extend their structure. In the current work, it was aimed to combine the synthesized 1,2,3-triazole ring system with 1,3,4-oxadiazole ring system in one molecule to obtain new heterocyclic compounds such as 11-15 as described in Scheme 3. To achieve this aim, the synthesized 1,2,3-triazole derivatives 6-10 and semicarbazide hydrochloride were condensed in the presence of $\mathrm{POCl}_{3}$. The latter is a chlorinating reagent for carboxyl function, which either used as such or in combination with a solvent.<smiles>[X]c1ccc(-n2cc(C(=O)O)nn2)cc1-n1cc(-c2nnc(N)o2)nn1</smiles>

Scheme 3. Synthesis of 1,3,4-oxadiazole derivatives

The synthetic route that was devised for the synthesis of the target compounds 11-15 followed the procedures that were described in the litertures ${ }^{25,26}$. The key step in this synthetic route is formation in situ the intermediate acylsemicarbazides, followed by a dehydro-cyclization reaction according to a general mechanism that is shown in Scheme 4. In general, this reaction was preceded smoothly without a problem seen to obtain the target compounds $11-15$ in a simple work up and pure enough. The structure of the synthesized compounds $6-15$ were characterized by FT-IR, ${ }^{1} \mathrm{H}-\mathrm{NMR}$ and Mass spectra.

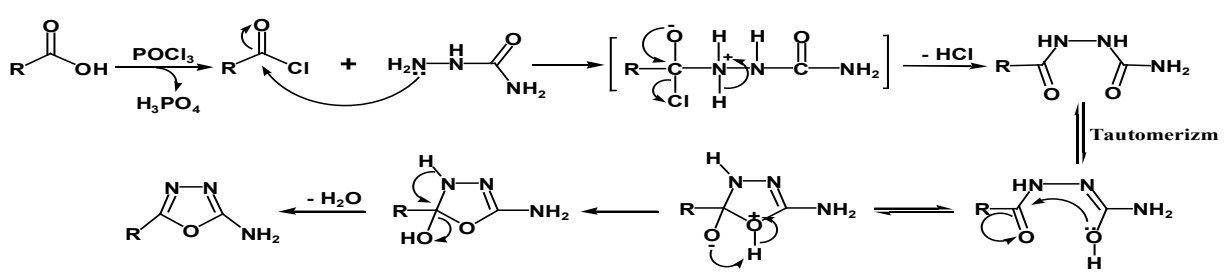

Scheme 4. A general mechanism for the synthesis of 1,3,4-oxadiazoles derivatives ${ }^{27,28}$ 


\section{Thermal behavior study}

Thermal analysis is an important technique used to investigate the thermal behavior of compounds such as a presence of intermediates, degradation process, melting and final known composition $^{29-31}$. In the current study, the thermal analysis of the target compounds 6-15 was achieved by using TGA combine DTG techniques. Thermo gravimetry (TG) is a useful analytical technique used for thermal analysis that is used for recording weight losing of a tested sample as a function of temperature ${ }^{32}$. While, DTG curves help to permit the direct application of the rate function of the change in the weight of the target sample to the study of phenomena occurring during thermo gravimetric analysis. Where, the area of the peak $\left(T_{\text {initial, }}, T_{\text {final }}\right)$ is directly proportional to the mass loss over the same temperature range and the DTG peak high at any temperature gives the rate of mass loss (dm/dT in $\mathrm{mg} /$ min unit) ${ }^{33}$. Practically, depending on the nature of the $\mathrm{m}$-, $\mathrm{p}$-, o-rich or poor-electron substituted phenyl that is attached to N1-position of 1,2,3-triazole ring, TG-DTG curves of compounds 6-10 are depicted in Fig. 2 and 3 . It is evident from these figures and Table 1 that compounds $6,7,8,9$ and 10 are thermally stable up to $205,223,182,135$ and $222^{\circ} \mathrm{C}$, respectively, followed a single decomposition stage. In addition, as expected compounds 8 and 9 displayed a less thermal stability due to their structures contain nitro group which can be described as thermally unstable group. Since, 1,3,4-oxadiazole ring system is considered a thermally stable species, TG-DTG measurements indicated that the synthesized compounds 11-15 have a higher thermal stability than their precursors $6-10$ up to $205^{\circ} \mathrm{C}$ then decomposed in a single stage as shown in Fig. 4 and 5 and Table 1.

\section{Table 1: TG-DTG data of compounds 6-15}

\begin{tabular}{|c|c|c|c|}
\hline Comp. No & $\begin{array}{c}\text { TG decomposition } \\
\text { temperature } \\
\text { Range }\left({ }^{\circ} \mathrm{C}\right)\end{array}$ & Losing weight (\%) & DTGmix $\left({ }^{\circ} \mathrm{C}\right)$ \\
\hline 6 & $205-302$ & 49 & 258 \\
\hline 7 & $223-243$ & 51 & 234 \\
\hline 8 & $182-232$ & 42 & 220 \\
\hline 9 & $135-195$ & 97 & 188 \\
\hline 10 & $222-283$ & 29 & 235 \\
\hline 11 & $250-378$ & 30 & 342 \\
\hline 12 & $206-403$ & 23 & 326 \\
\hline 13 & $248-363$ & 31 & 327 \\
\hline 14 & $215-382$ & 24 & 285 \\
\hline 15 & $238-402$ & 38 & 343 \\
\hline
\end{tabular}

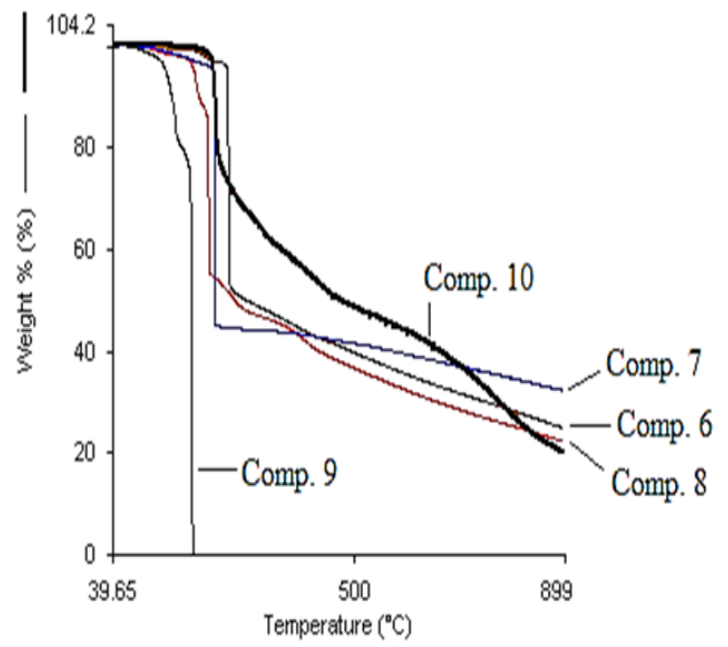

Fig. 2. TG curves of compounds 6-10

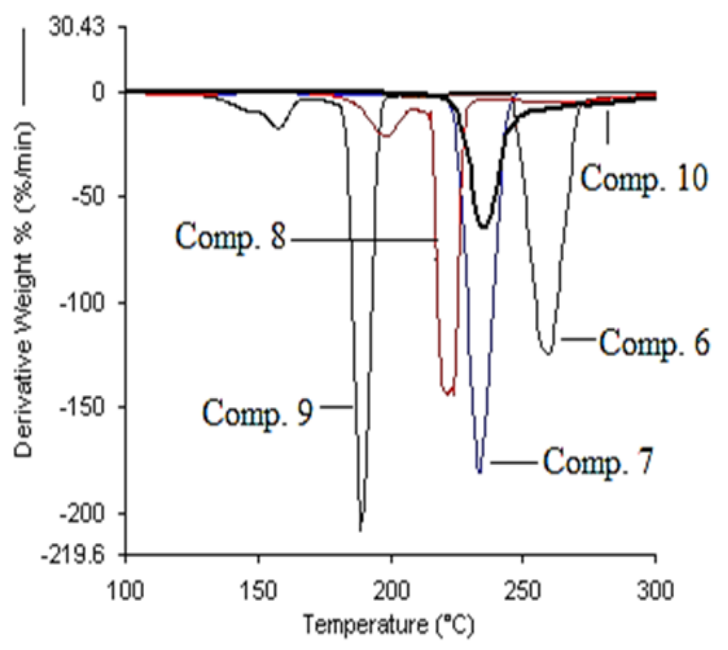

Fig. 3. DTG curves of compounds 6-10

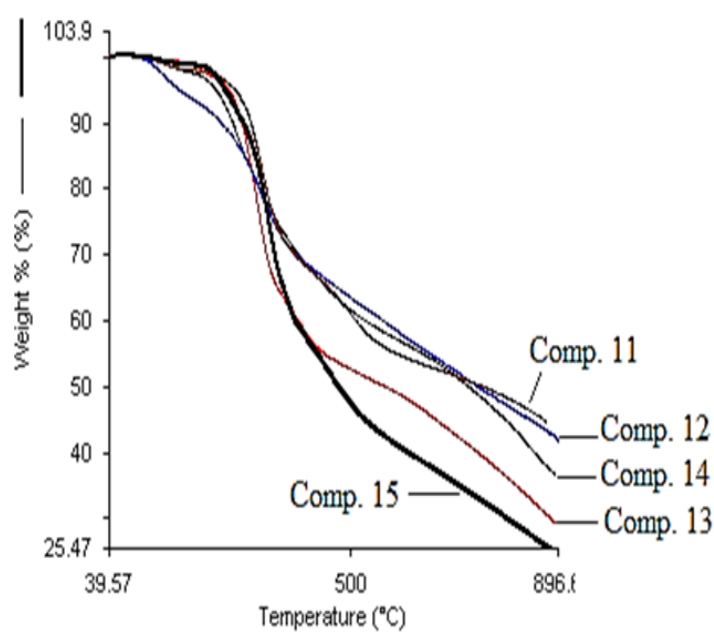

Fig. 4. TG curves of compounds 11-15 


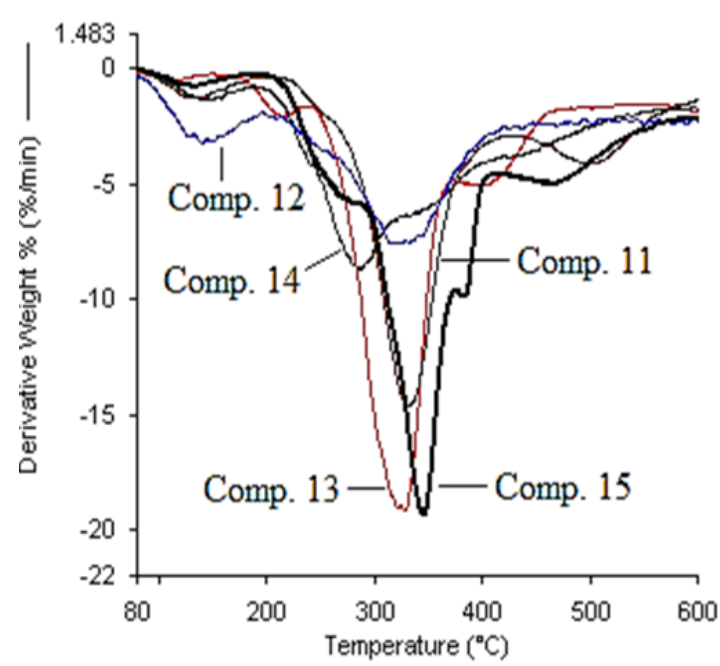

Fig. 5. DTG curves of compounds 11-15

\section{CONCLUSION}

In conclusion, a series of electron-rich and poor phenyl azide compounds displayed a reactivity to react with propiolic acid via click reaction (CuAAC). Since the synthesised 1,2,3-triazole derivatives containing a carboxyl functional group, it used to extend their structure with 2-amino-1,3,4-oxadiazole ring system via reaction with semicarbazide hydrochloride in the presence of $\mathrm{POCl}_{3}$. Furthermore, all synthesized heterocyclic compounds displayed a relatively good thermal stability.

\section{ACKNOWLEDGMENT}

The authors would like to thank the department of chemistry/College of Science/Al-Muthanna University for the facilities during doing this work.

\section{REFERENCES}

Cam-Van, T.; Bode, J.W. J. Org. Chem., 2014, 11 79, 2809-2815.

Saraswat, G.; Jeyabalan, P.; Hassan, U.; Mujeeb, M.Z.; Nyola, N. K. Synth. Commun., 2016, 46, 1643-1664.

Taylor, R. P.; Robinson, A. P.; Fobian, D. C.; Blakemore, Y. M.; Jones ,O.; Fadeyi, L. H. Org. Biomol. Chem., 2016, 10, 1039-1063.

Seeka,S.;Narsimha,S.;Reddy,V.N.;Savithajy ostna T. Der Chem. Sin., 2015, 6, 68-73.

Otero, N.; Estévez, L.; Mosquera, R. A. Eur. J. Org. Chem., 2012, 10, 2403-2413.

Schulze, B.; Schubert, U. S. Chem Soc Rev., 2014, 8, 231-269.

Dobrota, L.; Paraschivescu, C.; Dumitru, C.; Matache, I.; Baciu, M.; Rut, I. Tetrahedron Lett., 2009, 50, 1886-1888.

González-olvera, R.; Espinoza-vázquez, A.; Negrón-silva G. E.; Palomar-pardavé, M. E.; Romero-romo, M. A.; Santillan R. Molecules., 2013, 18, 15064-15079.

Jardo, A. K.; Ferreira, V. F.; Souza, T. L.; Faria, G. S.; Machado, V. Bioorg. Med. Chem., 2011, 19, 1860-1865.

Faraz, K. M.; Garima, V.; Wasim, A. Int. J. Drug Dev. Res., 2017, 9, 22-25.
Tornøe, C. W.; Christensen, C.; Meldal, M. J. Org. Chem., 2002, 67, 3057-3064.

Rostovtsev, V. V.; Green, L. G.; Sharpless, K. B. Angew. Chem. Int. Ed., 2002, 41, 2596-2599.

13 Singh, M. S.; Chowdhury, S.; Koley, S. Tetrahedron., 2016, 72, 5257-5283.

14 Stefani, H. A.; Silva, C. N.; Manarin, F. Tetrahedron Lett., 2012, 53, 1742-1747.

15 Lal, K.; Kumar, A.; Pavan, M. S.; Kaushik, C. P. Bioorg. Med. Chem. Lett., 2012, 22, 4353-4357.

16 Aufort, M.; Herscovici, J.; Bouhours, P.; Moreau, N.; Girard, C. Bioorg. Med. Chem. Lett., 2008, 18, 1195-1198.

17 Zachariah, S. M.; Ramkumar, M.; George N. Res. J. Pharm. Biol. Chem. Sci., 2015, 6, 205-219.

18 Gadegoni, H.; Manda, S. Chinese Chem. Lett., 2013, 24, 127-130.

19 Maghari, S.; Ramezanpour, S.; Darvish, S.; Balalaie, F. Tetrahedron., 2013, 69, 2075-2080.

20 Kumar, S.; Sundaree, D.; Johnson, K.; Shah, E. Bioorg. Med. Chem. Lett., 2009, 19, 4492-4494.

21 Guin, S.; Ghosh, T.; Rout, S. K.; Banerjee A.; Patel, B. K. Org. Lett., 2011, 13, 5976-5979. Oliveira, P.; Lira, C.; Barbosa-filho, B.; Gonçalo, J.; Lorenzo, J.; Athayde-filho, F. Molecules., 2012, 17, 10192-10231. 
23 Lima-neto, N.; Cavalcante, R.; Srivastava A.; Wanderley R.; Neves, J.; Anjos R. Molecules., 2012, 17, 5882-5892.

24 Li, L.; Zhang. Z. Molecules., 2016, 21, 1-22. 30

25 Verma, S.; Pandey, S.; Srivastava, O.; Pandey, A. J. Appl. Chem., 2017, 10, 1-7.

26 El-Karim, A.; Amine, I.; Mahmoud, M. S. J 32 Surfact Deterg., 2014, 17, 509-523.

27 Kolli, S. K. World. J. Pharm. Pharm. Sci., 2016, 33 5, 1800-1825.
28 Hameed, I.; Al-daraji, A. H.; Al-qaysi, R. R. Arab. J. Chem., 2010, 7, 687-694.

29 Jain, S.; Sharma, M. P. Fuel., 2012, 93, 252-257. 30 Mu-hoe,Y.; Yeuh-hui, L. J. Test. Eval., 2009, 37, 1-7. $31 \mathrm{Na}, \mathrm{D} . ;$ Yu-feng, Z.; Yan, W. Waste Manag., 2008, 28, 1572-1580.

Juarez, E.J.; Hawash, Zafer.; Sonia R.R.; Luis, K.O.; Qi, Y. Energy Environ. Sci., 2016, 9, 3406-3410. Chen, Z.; Hu, M.; Zhu, X.; Guo, D.; Liu, S.; Hu Z. Bioresour. Technol., 2015, 192, 441-450. 